The Geneva Papers on Risk and Insurance, 23 (No. 89, October 1998), 530-539

\title{
Developing Tomorrow's Leaders Today
}

\author{
by Norman A. Baglini*
}

The global financial services business is undergoing an astounding transformation due to consolidation of major providers, competition from new players, and changing consumer preferences. To survive and prosper in this new environment, financial services organizations must invest today in the development of their future leaders. The objective of this paper is to briefly explore some aspects of study and experience crucial to the development of successful leaders of financial services organizations in the beginning of the twenty-first century. Many of the ideas and examples in this paper have come from six years' involvement with on-campus education programs for executives from financial services firms around the world at the Wharton School of the University of Pennsylvania. The content of this paper does not represent the views of the Wharton School nor the views of the insurance institutes in the United States who sponsored these programs.

Jack Welch, Chairman and CEO of General Electric Corporation said, "Whether we like it or not, the future is going to be different from the present and the rate of change will not be evolutionary, it will accelerate and the patterns of change themselves will change." Observations such as this in speeches and seminars capture the attention of those who might not fully appreciate the profound developments in the business world and call for a reexamination of how to develop tomorrow's leaders. The traditional ways no longer work - they are based on a business environment that no longer exists and on a presumption that what has worked in the past will work in the future.

Instead, executive education should take the form of a program of individual development in four areas - personal, group, organization, and industry (or business). An executive education program must be dynamic. It should accommodate new educational

* Ph. D., CPCU, CLU, Chairman and Chief Executive Officer, American Institute for Chartered Property Casualty Underwriters, Insurance Institute of America, Insurance Institute for Applied Ethics, Malvern, PA. Prepared for the Geneva Association on the occasion of its 25the Anniversary, 1998. 
needs that derive from new ideas and concepts. Such an approach is extremely challenging because some of the skills that will be required in the future may not even be known at this time! Following is an overview of these four crucially important areas of development and ways in which they can be nurtured and strengthened.

\section{Development as a person}

Perhaps the most important development area is personal development, which is essential to the other three areas (group, organization, and industry). Of paramount importance in personal executive development are the following goals:

1. leading, coaching, and motivating a diverse workforce in a changing environment,

2. managing ethically,

3. communicating effectively, and

4. understanding systems thinking.

To meet these goals, much individual attention is necessary to (1) reinforce the strengths that each individual has and, (2) identify the areas for needed development. As a starting point, a 360-degree feedback instrument can provide insights into personal strengths, weaknesses, and potential "blind spots". A confidential questionnaire completed by the subject's boss, peers, and direct reports. can give a complete panoramic (360-degree) view of how the person in question is perceived by those with whom he or she works. Does he or she come across differently to those being supervised than to peers (coworkers at the same level)? Does the subject work cooperatively with his or her boss but appear to be a tyrant to underlings? This confidential look at a leader's style can provide priceless information that could engender a change in style - a change that could mean the difference between success and failure as a leader.

\subsection{Leading, coaching, and motivating}

Much has been written and spoken about the leader of tomorrow as a coach, mentor, and motivator. In contrast, the leader of the past tended to be an autocrat who used power to impose his (there were no women at the top in the past) will on others. One of the critical success factors in selecting tomorrow's leaders will be their ability to unleash the power to innovate and to serve that lies in each properly trained employee. Sessions on "executive skills portfolios" and "learning styles inventory" (a questionnaire that identifies an individual's way of learning) and others can be directed to this increasingly important area of personal development. (The term session is used here rather than class, to emphasize the presenter's role as facilitator rather than a lecturer. A session may be one or two hours or several hours over a period of weeks.)

\subsection{Managing ethically}

Recently, much of the management literature has supported the importance of ethics as an increasingly vital characteristic of leaders. The ethical qualities mentioned include honesty, integrity, and trustworthiness. Given the traumatic dislocations common in large corporations, it is not surprising that honest and trusted leaders whose actions are consistent with their words and sought after by corporate boards and employees. 


\subsection{Communicating effectively}

Many brilliant minds are mashed in people who have difficulty communicating their ideas. Financial services are becoming increasingly complex and the ability to explain complex concepts in understandable layman's language is critical to everyone from the chief executive officer to the customer service representative. Top managers must make presentations to their boards of directors, stockholders, and stock analysts, and the quality of the delivery of the report is often as important is the message itself. This is especially the case in difficult times when the audience is evaluating the truthfulness, candor, and confidence of the leader.

Like leadership, communication is developed through observation and remedial action. Each participant's communication style can be observed through prepared presentations that are videotaped and critiqued. This individual attention is well worth the time invested in it. Some careers are greatly enhanced as a result of just one such experience! In addition, there can be opportunities to observe how the participants communicate among their peers when working on small group projects. Finally, when the small groups report back to the entire class, the selected spokesperson can be observed and evaluated by those who have been trained to do so.

\subsection{Systems thinking}

In the increasingly complex and interrelated business world, the leader of tomorrow must understand systems thinking. While every businessperson would acknowledge that a business unit is a system, the management of increasingly complex financial services organizations will require a new way of thinking about the business unit as a system. According to Dr. Russell L. Ackoff, Emeritus Professor-University of Pennsylvania and President of Interact, a management consulting firm, a business enterprise should be viewed as a social system. Any system consists of a set of parts or elements, each of which can affect the essential function, behavior, or properties of the whole. The way each part affects the whole depends on what at least one other part is doing; that is, no part has an independent effect on the whole. Every possible subgroup or part can also affect the essential function, behavior, or properties of the whole, but none can do so independently of all other parts. Therefore, a system is a whole that cannot be divided into independent parts ${ }^{1}$.

The prevailing concept of management is based of the contradictory and false assumption that if the performance of each part of an organization is improved, the performance of the whole organization will be improved ${ }^{2}$. When a system is taken apart, it loses its essential function, behavior or properties, and so do its parts. The essential characteristics of a system depend on how its parts interact, not on how they act separately. The performance of a system is not the sum of its parts' performance but the product of their interactions.

The implications of Ackoff's systems thinking approach to a financial services firm are enormous. Most managers "manage" by moving from one function to another, such as

${ }^{1}$ Ackoff, Russell L., Class notes on Systems Thinking, Advanced Executive Education (AEE) program, The Wharton School, March 1997.

${ }^{2} \mathrm{Ibid}$. 
underwriting, claims, customer service, actuarial, and so on, working with their direct reports in those functions to solve problems and improve performance in that function, even to the extent of "micro managing." Instead, Ackoff would suggest leaving the management of the parts of the system (the functions of underwriting, claims, and so on) to the properly trained and empowered managers and directing top management's efforts to the interactions of these functions. The trend toward work teams, consisting of fairly autonomous small groups representing various functions, is an example of the importance of managing the interactions of the parts rather than the parts themselves. This is especially important when the firm is planning a merger, an acquisition, or an expansion into a new area of financial services. The attractive but elusive "synergy" upon which so many consolidations are based cannot come about without careful management of the interaction of all the parts of the system. Top management must not only know how the parts of the organization interact, but must have a vision of how the interactions must work to improve the performance of the organization as a whole.

\section{Development as a group}

Everyone in business is part of a relatively small working group whether it is the president's senior staff, the strategic planning team, the senior underwriting staff, and so on. Each has his or her own experience, positive and negative, working with various groups. Those experiences can influence that individual's effectiveness in working with other groups, including those industry or government groups where outcomes may depend on the "voluntary followship" of others. Because working in groups is best observed and learned by actually doing it, much of the design of executive education programs should be directed toward projects for small groups (5 to 7 people with diverse backgrounds) working together under time pressure to achieve a specific objective. Following are examples of some small group industry-specific projects:

1. a project to globalize a one country financial services firm,

2. an insurance company management computer simulation game,

3. an exercise where roles are changed (reinsurers become customers, brokers become insurers, etc.), and

4. an action learning project-an extensive research project that takes place between the terms of residence on campus (explained later).

\section{Development as an organization}

Perhaps more time should be spent in this area of development than in any other because of the rate and magnitude of consolidation in financial services with their resulting impact on organization structure and organization dynamics. Accordingly, some of the sessions in executive education should be directed to:

1. mergers, acquisitions, and strategic alliances and their effect on corporate culture,

2. becoming a learning organization,

3. marketing strategy and competitive dynamics,

4. managing technology and innovation as a strategic asset,

5. enhancing shareholder value, 
6. implementing strategy, and

7. the CEO's perspective,

8. creating the corporate future.

Numbers 1,2 and 4 in the list above will be briefly explained.

\subsection{Consolidation and corporate culture}

Tomorrow's corporate leaders must be able to manage the many details of implementing a major consolidation or series of mergers and acquisitions. They must be keenly aware of the impact of consolidation on corporate culture. When organizations merge, or when one acquires another, the culture of the new organization is not established at the stroke of the pen. Corporate culture is developed over time. It consists of the values that guide the organization, its traditions, its way of doing business, and how it treats its customers, suppliers, and employees.

In the past when companies were much smaller, corporate culture was often established, deliberately or not, by the firm's founders. It was often an extension of the founders' personal values, and because the founders were respected and because they wielded great power, their values became the unwritten but well understood code of conduct throughout the firm. More recently, the power to establish the firm's culture was passed along to the corporate leaders, especially the chief executive officer (who may or may not have an interest in it). Many corporations, even some of the largest, have earned a much-envied reputation for integrity, honesty, and promise keeping from customers, competitors, and employees through the leadership of top management.

After a consolidation, which corporate culture will emerge? In an acquisition, it would appear to be the culture of the acquiring company since the acquired company will be out of business, but that is not always the case. In a true merger of equals, the question of culture may not be answered for some time as key people come and go and as corporate policies are examined and often modified. During this period, clients, employees, and others look for clues as to the nature of the new entity. Every press release, memo, or other communication is carefully analyzed (sometimes erroneously) with the hope of gleaning a bit more information regarding the culture of the new entity. Unfortunately, during this time, some firms have received adverse publicity due to unethical and sometimes illegal actions of employees who have not had the benefit of a clearly articulated statement of ethics and compliance. Here, the role of the leaders is crucial. A carefully worded and comprehensive corporate code of ethics that is widely distributed throughout the entire organization can do much to minimize the chance of an illegal or unethical act that could severely affect the image and perceived value of the new entity. It has been said that a code of ethics will do nothing to increase corporate earnings. While this statement is debatable, it is obvious that a code of ethics can help save money by keeping the company out of trouble. Only top management can see that this is accomplished.

\subsection{Becoming a learning organization}

Peter Senge's book, The Fifth Discipline, The Art and Practice of the Learning Organization, published in 1990 , introduced the notion of a corporation as a "learning 
organization." Ray Stata, chief executive officer of Analog Devices, stated, "The rate at which organizations learn may become the only sustainable source of competitive advantage, especially in knowledge-intensive businesses. ${ }^{\text {" }}$ "Four keywords should be stressed:

- It is the rate of learning that has the potential for competitive advantage. The organization that learns the fastest and acts on what it has learned will capitalize on its learning before others.

- It is the learning of organizations rather than the learning of individuals that is emphasized here. Since corporate goals depend upon the performance of the entire organization, becoming a learning organization must be given a high priority by top management who should give continuous visible support to its importance.

- It is the sustainability of a competitive advantage that makes it worth pursuing. Very few things in business can be considered sustainable. Organizational learning can make a difference in the long-term success of the firm.

- It is the knowledge-intensive businesses that benefit most from organizational learning. There is no question that all financial services firms are knowledge intensive knowledge of financial trends, knowledge of financial products and regulations, knowledge of consumer needs and demands, knowledge of information sources, knowledge about motivating and leading knowledge workers, and so on.

Despite the widespread acceptance of the importance of organizational learning, some organizations unknowingly allow obstacles that prevent it from becoming part of the corporate culture. An anti-learning organization is the unintended result. According to Michael Felts, CPCU, American Reinsurance Company, anti-learning can result from:

- attempting to unilaterally control a situation,

- taking our own reasoning for granted,

- believing unchecked inferences to be facts,

- minimizing inquiry into others' views,

- needing to win at all costs, and

- promoting face saving 4 .

\subsection{Managing technology as a strategic resource}

The leaders of tomorrow's financial services corporations must not only be very comfortable with information systems and technology, they must be technically proficient with it! Such is the profound effect of technology on the future of financial services. It is essential in providing superior customer service, expanding globally, and in responding quickly to new market opportunities. In fact, technology plays a key role in enabling firms to globalize.

\footnotetext{
${ }^{3}$ Senge, Peter M., The Leader's New Work: Building Learning Organizations, Sloan Management Review, Volume 32, Number 1, Fall 1990.

${ }^{4}$ Felts, Michael, Class notes on the Anti-Learning Organization, Advanced Executive Education (AEE) program, The Wharton School, September 1997.
} 
Information systems and technology can also aid top management in its strategic thinking and decision making. Unfortunately, it appears that few firms have actually succeeded in managing their technologies as a strategic resource. Instead, it is considered a secondary resource driven by the demands of strategy implementation rather than strategy formulation ${ }^{5}$. Organizational inertia and corporate culture have been implicated as obstacles, but "techno-phobia" and technological myopia especially on the part of top management are contributing factors. While technical experts should be empowered to deal with the tactical and operational issues, top executives must accept their responsibility in integrating technology into strategic management, including strategic planning, which is typically dominated by marketing and financial issues.

According to William F. Hamilton, Landau Professor of Management and Technology at the University of Pennsylvania:

1. While top managers recognize the importance of technology, they tend to be distant from it.

2. In ranking most trusted advisers to CEOs, technology experts ranked ninth, just after comptrollers.

3. Technology is too important to leave to the technologists.

4. Obstacles to successful technological innovation are more managerial than technical6.

\section{Development as an industry}

Second only to development as an organization, this area is as dynamic as the financial services business itself. As current events unfold, the topics in this section can be changed to meet current and future needs. At the risk of seeming out of date, some sessions at Wharton have been devoted to:

1. international financial markets and international diversification of investments,

2. new developments in risk financing including securitization of risks,

3. prediction of natural catastrophes,

4. economic outlook for financial services around the world,

5. empowerment and a changing workforce, and

6. electronic commerce.

Given the interdependence between the financial markets around the world, an understanding of them is critically important. Case studies and analysis of current events should provide the backdrop for this learning experience.

One of the most dynamic sessions is new developments in risk financing. Almost weekly, the trade press carries yet another story of a new, if experimental, risk financing program developed jointly by a demanding corporate risk manager, a visionary broker or consultant, an open-minded underwriter, and sometimes others including innovative

\footnotetext{
${ }^{5}$ Hamilton, William, Class notes on Managing Technology and Innovation, Advanced Executive Education (AEE) program, The Wharton School, March 1997.

${ }^{6}$ Hamilton, William, Class notes on Managing Technology and Innovation, Advanced Executive Education (AEE) program, The Wharton School, March 1997.
} 
financial experts. The recent series of enormous natural catastrophes and the potential for more call for creative approaches to financing risks. The combined capital and surplus of the worldwide property and casualty insurance business will not be sufficient for the huge potential natural catastrophes. For example, the combined capacity of the property and casualty insurance business in the United States is approximately $\$ 260$ billion, whereas the U. S. capital markets are approaching $\$ 14$ trillion! Many investors are looking for an asset class that is not affected by the same general economic conditions and interest rate movements as are all their other investments. Since there is no relationship between the occurrence or non-occurrence of a natural catastrophe and interest rates, there appears to be a market for "cat" bonds as a source of risk financing.

Sophisticated computer models are now being used to predict hurricanes and earthquakes. Analysis of such models and discussions with geologists help the participants to better understand how to protect their companies' assets from these events.

Economists who specialize in financial services forecasting, experts in workforce issues, and creative marketers who envision amazing marketing potential through the internet are just a few other resources that must be brought to the executive education experience. As long as the financial services industry continues to evolve, the list of topics will continue to grow.

\section{Delivering executive education}

Even the best thought out curriculum that perfectly matches the needs of the learners might not be successful if improperly delivered. Activities that allow the participants to apply new concepts are essential, as are opportunities to exchange ideas and experiences in areas not necessarily included in the curriculum.

\subsection{The setting}

To allow people to think differently and to be receptive to new ways of analyzing their business or their organization, they should be taken from their familiar surroundings where patterns of thought have become routine and inflexible. An urban university campus with access to leading business leaders and faculty works best and provides opportunities to quickly schedule new sessions requested by the participants because of the proximity to the facilitators. The setting should be quiet to allow for the reflection necessary to question, analyze, and absorb the newly obtained information, and to provide a contrast from the participants' usual work environment and workday routines. If possible, the learning and living quarters should be in the same building to minimize the disruption of commuting or to avoid the effects of inclement weather if activities take place in different buildings on the same campus.

Sleeping rooms should be equipped with personal computers with Internet access for research. Small group "break out" rooms should be available 24 hours a day for the groups to meet and leave the results of their work on blackboards or flipcharts. They should be relatively close to the large group meeting room to minimize time moving between each location. 
Being in an urban area makes it possible to schedule cultural events, sporting events, and other activities that permit the participants to get to know one another very well and also allows discussion of important topics to continue.

\subsection{Group project design and implementation}

The various group projects must fit the needs of the participants, although each has a different educational background, work experience, and cultural heritage. Yet, they must learn how to learn from one another. Moreover, as experienced business executives, they have much knowledge that can benefit the entire group. The group projects should allow each to share his or her "wisdom" without the need to divulge any personal or company confidential information, and should stimulate thinking in every individual regardless of background.

The major project - Action Learning - takes place between terms on campus to allow time for the groups to conduct research and finalize the project while each member is back "on the job" with all the usual distractions and deadlines. The major purposes of the action learning project are to (1) sharpen research skills, and (2) meet a tight deadline through a group spread out around the world and without a formally appointed leader. Being geographically dispersed requires the use of e-mail and teleconferencing-techniques that are required of future leaders.

Likewise, achieving an objective in a group without a formally appointed leader may be the rule rather than the exception in the business world of tomorrow-a world of fastmoving, ever changing working relationships.

\subsection{The facilitators (faculty)}

Effective implementation is the role of the facilitators (faculty) who are discussion leaders more than lecturers. It is far more difficult to be an outstanding facilitator with a keen eye and ear to determine if learning is taking place than to be a well-informed and articulate lecturer. While the participants expect to benefit from the "accumulated wisdom" and recent research or consulting experience of the presenter, it is through questions to and from the group, and the interaction that true learning takes placelearning that is largely dependent upon the skills of the facilitator.

To encourage new ways of thinking, the facilitators may be drawn from numerous disciplines. For example, an anthropologist with an interest in businesspeople can help them to think "like a scientist" and escape from some habitual decision traps. Additionally, economists, geologists, psychologists, and others can add much to opening the minds of these future leaders.

\subsection{Selection of participants}

The success of an executive education program is determined, in part, by assembling a diverse group with similar learning needs. There is richness in diversity, with each contributing to the learning of the other. In fact, feedback from attendees indicates that some of the most memorable and lasting lessons were learned from informal relationships with classmates. When assigning people to the small 5 to 7 member work groups, much 
thought is given to how each could contribute something different, a task not dissimilar to assembling a corporate-wide project team.

\subsection{Reflecting, rethinking and revitalizing - a benefit of executive education}

In his highly acclaimed book, "The 7 Habits of Highly Effective People," author Stephen R. Covey calls the seventh habit-"sharpen the saw." He explains that people today are so busy sawing (producing, managing, planning,) that they don't take time to sharpen the saw-an act that would greatly improve efficiency. By sharpening the saw, Covey is referring to rest, recreation, study, reflecting, rethinking, retooling, and revitalizing. Additionally, these very busy people often fail to invest in new power sawsthose new technological tools and new ways of thinking and working that would improve performance.

\section{A role for the Geneva Association?}

During its 25-year history, the Geneva Association has initiated, fostered, and developed many outstanding educational opportunities from journals to lectures and seminars. From its prominent position as a leader in risk and insurance education, it might now consider identifying the educational needs of the future leaders of the financial services business. Since the Geneva Association is so well known and highly regarded, it would be in an excellent position to work with appropriate universities with extensive executive education experience to develop a series of programs that could do much to ensure the growth and prosperity of the companies the Geneva Association so ably serves. 